Глава 6. Физиология и биохимия растений

22. Wang F, Yang S, Guo F, Meng J J, Meng Q W, Wan S B, Li X G. Effect of calcium on peanut (Arachis Hypogae L.) seedling growth, accumulation of reactive oxygen species and photoinhibition // American Journal Plant Science. - 2015. - Vol. 35. - № 15. - P. 14961504. - doi: 10.5846/stxb201305070965.

\title{
PHOTOSYNTHETIC ACTIVITY \\ OF MATURE TEA LEAVES IN EARLY SPRING WITHIN APPLICATION OF VARIOUS FERTILIZERS IN THE CONDITIONS OF RUSSIAN SUBTROPICS
}

\author{
Veliky A. V. \\ Federal Research Centre \\ the Subtropical Scientific Centre of the Russian Academy of Sciences, \\ c.Sochi, Russia,e-mail: kriptozoorxon@mail.ru
}

In the conditions of field experiment with fertilizers, the photosynthetic activity of tea plants in the early spring period was evaluated by the parameters of slow induction of chlorophyll fluorescence. It was established that calcium-containing substance and boric acid applied in soil influenced on the chlorophyll fluorescence, as well as there was recorded an aftereffect of zinc sulfate. The tendency of positive influence from calciumcontaining substance on the viability index of mature leaves was noted in March, which made it easier for plants to bear various stressful conditions in the winter period.

Key words: tea, fluorescence, slow chlorophyll induction, viability index, photosynthetic activity, biogenic elements, calcium, boron, zinc.

\section{ВОДНЫЙ РЕЖИМ ПРЕДСТАВИТЕЛЕЙ РОДА CHRYSANTHEMUM ПРИ ИНТРОДУКЦИИ НА ЮЖНОМ УРАЛЕ}

\author{
Денисова С. Г., Реут А. А. \\ Южно-Уральский ботанический сад-институт - \\ обособленное структурное подразделение Федерального государственного \\ бюджетного научного учреждения Уфимского федерального \\ исследовательского иентра Российской академии наук, \\ 2. Уфа, Pоссия, e-mail: svetik-7808@mail.ru
}

В статье представлены результаты сравнительного изучения водного режима 23 сортов хризантем, интродуцированных в Южно-Уральский ботанический сад-институт - обособленное структурное подразделение Федерального государственного бюджетного научного учреждения Уфимского федерального исследовательского центра Российской академии наук. Дана оценка общей оводнённости, водоудерживающей способности, суточной потери влаги и водного дефицита в течение вегетационного периода 2018-2019 гг. Показано, что сорта хризантем 
в условиях Башкирского Предуралья при одинаковых почвенно-климатических и агротехнических условиях имеют различную степень засухоустойчивости. В целом изученные сорта хризантем оказались пригодными для выращивания в лесостепной зоне Башкирского Предуралья.

Ключевые слова: хризантема, водный режим, общая оводнённость, водоудерживающая способность, водный дефицит.

Хризантема корейская (Chrysanthemum coreanum (Levl. \& Vaniot) Nakai) - многолетнее растение гибридного происхождения - востребованная осеннецветущая культура для садово-паркового оформления и использования на срез, отличается продолжительным, обильным и красочным цветением. Её родина - Китай. В мире в настоящее время существует около 5000 сортов. В средней полосе России выращивают в открытом грунте около 200. Однако внедрение её в климатическую зону Республики Башкортостан ограничено отсутствием сортов, адаптированных к местным условиям, и обоснованного ассортимента.

Одна из основных задач современной биологии состоит в исследовании особенностей существования организма в зависимости от экологических факторов. Большинство стрессовых воздействий изменяют водный режим растений [12]. Водный стресс вызывает повреждения растений на разных уровнях их организации: дегидратация содержимого клеток, обусловленная засухой, приводит к потере тургора, снижению водного и осмотического потенциала, интенсивности и продуктивности фотосинтеза [6]. Несмотря на значительный прогресс в решении теоретических и практических вопросов адаптации растений, в настоящее время важны глубокие физиологические исследования с целью выявления ведущих эндогенных и экзогенных факторов, лимитирующих реализацию адаптационного потенциала растения в целом, или в конкретных агроклиматических регионах [13].

Показатели водного обмена также выступают как критерии для оценки устойчивости растений к неблагоприятным факторам среды [5, $9,10]$. При этом водоудерживающая способность (скорость водоотдачи листьями) является одним из важнейших физиологических показателей, диагностирующих устойчивость растений к засухе [1, 11].

В природных условиях полного насыщения листьев водой практически не бывает. Водный дефицит - это количество воды, недостающее до полного насыщения ткани, выраженное в процентах от количества воды, содержащейся при её полном насыщении. Водный дефицит особенно сильно возрастает в жаркую погоду, в связи с повышением интенсивности транспирации, при засухе или недостатке воды в почве. Водный 
дефицит, не превышающий 10 \%, представляет собой нормальное явление, не причиняющее растению вреда. Водный дефицит, достигающий 25 \% и более, приводит к закрыванию устьиц, завяданию листьев, снижению интенсивности роста и фотосинтеза, нарушению энергетического обмена и синтетической деятельности клеток [8].

Целью исследования было сравнительное изучение водного режима некоторых сортов хризантем при интродукции в Башкирское Предуралье.

Объекты и методы. Исследования проводились на базе ЮжноУральского ботанического сада-института - обособленного структурного подразделения Федерального государственного бюджетного научного учреждения Уфимского федерального исследовательского центра Российской академии наук (далее ЮУБСИ УФИЦ РАН) в вегетационный период 2018-2019 гг. Почвы на опытном участке серые лесные, типичные для региона, $\mathrm{pH}=6,14$.

Пробы листовых пластинок брали из средней части куста в три этапа (август, сентябрь, октябрь). Отбор осуществляли в утренние часы. Взвешивание проводили на лабораторных электронных весах Госмер ВЛТЭ 1100, высушивание образцов - в сушильном шкафу ШС-80-01 СПУ при температуре $105-110{ }^{\circ} \mathrm{C}$.

Оценка водного режима проводилась методом искусственного завядания в соответствии с указаниями В. Н. Таренкова, Л. Н. Ивановой [11]. Оценивались водоудерживающая способность, общая оводнённость и суточная потеря воды листьями. Водный дефицит и сопутствующие показатели (относительная тургесцентность) оценивали методом насыщения растительных образцов в соответствии с указаниями В. П. Моисеева и Н. П. Решецкого [8].

Объектами исследований стали 23 сорта Chrysanthemum coreanum ('Белоснежка', 'Відинский Бал’, 'Вечерняя Симфония’, ‘Дебют', ‘Загадка Осени', ‘Золотистый Дукат', 'Золотоволоска', 'Казачка', 'Клара Кертис', 'Клеопатра', 'Милашка', 'Опал', 'Пектораль', 'Перстень Королевы', 'Плюшевый Мишка', 'Солнечная Феерия', 'Солнышко', 'Танго', ‘Шапка Мономаха', ‘Яблуневый Цвіт’, 'Akiwa Yellow', 'Estino Whito', 'Grandeur'). Данные сорта были получены черенками из Центрального ботанического сада Национальной академии наук Беларуси (г. Минск) или из частных коллекций.

Математическую обработку экспериментальных данных проводили стандартными методами [2] с использованием статистических пакетов программы Microsoft Excel 2003.

Результаты и их обсуждение. Активная жизнедеятельность растений возможна только при высокой оводнённости их тканей, поэтому 
водный режим является одним из важнейших звеньев в цепи процессов, которые играют существенную роль в жизни растений, и представляет собой одну из центральных проблем экологической физиологии растений [4].

При анализе особенностей водного режима листьев изученных сортов хризантем выявлено, что их общая оводнённость менялась в течение вегетационного периода от 69,8 ('Шапка Мономаха') до 87,9 \% ('Золотоволоска') при среднем значении признака 79,5 \% (табл. 1). Водоудерживающая способность листьев колебалась от 12,8 ('Золотоволоска') до 54,2 \% ('Перстень Королевы’) при среднем значении признака 36,7 \%. Также выявлено, что средние показатели общей оводнённости снижаются к сентябрю и несколько увеличиваются в октябре.

Таблица 1

\section{Оценка водного режима некоторых сортов хризантем}

\begin{tabular}{|c|c|c|c|c|c|c|c|c|c|}
\hline \multicolumn{2}{|l|}{ Сорт } & \multicolumn{3}{|c|}{$\begin{array}{c}\text { Показатели } \\
\text { водного режима }\end{array}$} & \multirow{2}{*}{\multicolumn{2}{|c|}{ Сорт }} & \multicolumn{3}{|c|}{$\begin{array}{c}\text { Показатели } \\
\text { водного режима }\end{array}$} \\
\hline & & \multirow{2}{*}{$\frac{\mathrm{W}}{85,71}$} & \multirow{2}{*}{$\frac{\mathrm{R}}{20,88}$} & \multirow{2}{*}{$\frac{\mathrm{L}}{64,84}$} & & & \multirow{2}{*}{$\frac{\mathrm{W}}{81,91}$} & \multirow{2}{*}{$\frac{\mathrm{R}}{42,55}$} & \multirow{2}{*}{$\frac{\mathrm{L}}{39,36}$} \\
\hline \multirow{3}{*}{ 'Akiwa Yellow' } & $\mathrm{a}$ & & & & \multirow{3}{*}{ ‘Клеопатра’ } & $\mathrm{a}$ & & & \\
\hline & 6 & 84,05 & 29,37 & 54,68 & & 6 & 78,21 & 38,46 & 39,74 \\
\hline & B & 81,03 & 13,33 & 67,69 & & B & 80,95 & 29,13 & 51,82 \\
\hline \multirow{3}{*}{ 'Estino Whito' } & $\mathrm{a}$ & 82,59 & 33,83 & 48,76 & \multirow{3}{*}{ 'Милашка' } & $\mathrm{a}$ & 82,09 & 41,04 & 41,04 \\
\hline & 6 & 74,55 & 36,92 & 37,63 & & 6 & 77,96 & 46,77 & 31,18 \\
\hline & B & 82,30 & 31,42 & 50,88 & & B & 81,03 & 41,38 & 39,66 \\
\hline \multirow{3}{*}{ 'Grandeur' } & $\mathrm{a}$ & 84,06 & 42,03 & 42,03 & \multirow{3}{*}{ ‘Опал’ } & $\mathrm{a}$ & 81,16 & 44,57 & 36,59 \\
\hline & 6 & 81,19 & 33,03 & 48,17 & & 6 & 71,74 & 42,83 & 28,92 \\
\hline & B & 81,39 & 29,00 & 52,38 & & B & 79,42 & 39,47 & 39,95 \\
\hline \multirow{3}{*}{ ‘Белоснежка' } & $\mathrm{a}$ & 76,80 & 41,24 & 35,57 & \multirow{3}{*}{ 'Пектораль' } & $\mathrm{a}$ & 86,31 & 33,20 & 53,11 \\
\hline & 6 & 75,15 & 36,49 & 38,66 & & 6 & 80,72 & 45,15 & 35,58 \\
\hline & B & 76,53 & 31,30 & 45,23 & & B & 80,14 & 27,40 & 52,74 \\
\hline \multirow{3}{*}{$\begin{array}{l}\text { 'Відинский } \\
\text { Бал' }\end{array}$} & $\mathrm{a}$ & 85,11 & 37,23 & 47,87 & \multirow{3}{*}{$\begin{array}{l}\text { 'Плюшевый } \\
\text { Мишка' }\end{array}$} & $\mathrm{a}$ & 83,21 & 29,20 & 54,01 \\
\hline & 6 & 76,78 & 39,81 & 36,97 & & 6 & 74,26 & 48,35 & 25,91 \\
\hline & B & 76,35 & 26,35 & 50,00 & & B & 79,68 & 35,29 & 44,39 \\
\hline \multirow{3}{*}{$\begin{array}{l}\text { 'Вечерняя } \\
\text { Симфония' }\end{array}$} & $\mathrm{a}$ & 71,23 & 31,05 & 40,18 & \multirow{3}{*}{$\begin{array}{l}\text { Перстень } \\
\text { Королевы }\end{array}$} & $\mathrm{a}$ & 85,90 & 42,73 & 43,17 \\
\hline & 6 & 71,16 & 34,53 & 36,63 & & 6 & 74,84 & 54,14 & 20,70 \\
\hline & B & 74,73 & 27,08 & 47,65 & & B & 74,85 & 42,81 & 32,04 \\
\hline \multirow{3}{*}{ ‘Дебют’ } & $\mathrm{a}$ & 83,90 & 37,56 & 46,34 & \multirow{3}{*}{$\begin{array}{l}\text { ‘Солнечная } \\
\text { Феерия’ }\end{array}$} & $\mathrm{a}$ & 87,43 & 42,41 & 45,03 \\
\hline & 6 & 74,90 & 45,25 & 29,66 & & 6 & 75,94 & 49,79 & 26,15 \\
\hline & B & 79,30 & 40,70 & 38,60 & & B & 79,95 & 44,76 & 35,20 \\
\hline \multirow{3}{*}{$\begin{array}{l}\text { ‘Загадка } \\
\text { Осени’ }\end{array}$} & $\mathrm{a}$ & 86,42 & 37,04 & 49,38 & \multirow{3}{*}{ ‘Солнышко’ } & $\mathrm{a}$ & 84,24 & 24,85 & 59,39 \\
\hline & 6 & 76,25 & 46,25 & 30,00 & & 6 & 71,68 & 30,06 & 41,62 \\
\hline & B & 79,15 & 38,63 & 40,52 & & B & 71,33 & 16,67 & 54,67 \\
\hline
\end{tabular}


Глава 6. Физиология и биохимия растений

\begin{tabular}{|c|c|c|c|c|c|c|c|c|c|}
\hline \multirow{3}{*}{$\begin{array}{l}\text { ‘Золотистый } \\
\text { Дукат’ }\end{array}$} & $\mathrm{a}$ & 84,62 & 27,35 & 57,26 & \multirow{3}{*}{ ‘Танго’ } & $\mathrm{a}$ & 85,14 & 41,22 & 43,92 \\
\hline & 6 & 82,25 & 29,01 & 53,24 & & 6 & 78,35 & 45,58 & 32,76 \\
\hline & В & 81,79 & 30,87 & 50,92 & & B & 78,34 & 27,00 & 51,34 \\
\hline \multirow{3}{*}{$\begin{array}{l}\text { ‘Золото- } \\
\text { волоска’ }\end{array}$} & $\mathrm{a}$ & 87,82 & 35,90 & 51,92 & \multirow{3}{*}{$\begin{array}{l}\text { 'Шапка } \\
\text { Мономаха' }\end{array}$} & $\mathrm{a}$ & 75,66 & 50,00 & 25,66 \\
\hline & 6 & 78,22 & 32,21 & 46,01 & & 6 & 69,85 & 48,16 & 21,69 \\
\hline & $\mathrm{B}$ & 75,90 & 12,85 & 63,05 & & $\mathrm{~B}$ & 79,59 & 40,82 & 38,78 \\
\hline \multirow{3}{*}{ ‘Казачка’ } & $\mathrm{a}$ & 84,29 & 39,29 & 45,00 & \multirow{3}{*}{$\begin{array}{l}\text { ‘Яблуневый } \\
\text { Цвіт’ }\end{array}$} & $\mathrm{a}$ & 86,76 & 44,61 & 42,16 \\
\hline & 6 & 75,10 & 51,95 & 23,15 & & 6 & 76,05 & 46,20 & 29,85 \\
\hline & B & 80,95 & 44,26 & 36,69 & & B & 75,75 & 37,31 & 38,43 \\
\hline \multirow{3}{*}{ ‘Клара Кертис’ } & $\mathrm{a}$ & 82,99 & 39,46 & 43,54 & & & & & \\
\hline & 6 & 80,69 & 33,33 & 47,35 & & & & & \\
\hline & B & 77,65 & 22,91 & 54,75 & & & & & \\
\hline
\end{tabular}

Примечание: $\mathrm{W}$ - общая оводнённость;

$\mathrm{R}$ - водоудерживающая способность;

$\mathrm{L}$ - содержание «подвижной» влаги;

a - август; б - сентябрь, в - октябрь

Водоудерживающая способность тканей является одним из показателей водного режима, характеризующих способность растений переносить длительное обезвоживание. Она связана с процессами гидратации и иммобилизации воды структурными компонентами клетки и непосредственно с процессами метаболизма. Значения этого показателя - динамичная величина [7]. В результате нашего исследования установлено, что у 65,2 \% сортов показатель водоудерживающей способности увеличивался к сентябрю на 3,6 ('Яблуневый Цвіт’) - 65,6 \% ('Плюшевый Мишка') по сравнению с данными августа. Через месяц (в октябре) отмечалось уменьшение на 10,0 ('Дебют’) - 54,6 \% ('Akiwa Yellow'). У 30,4 \% сортов в течение вегетационного периода наблюдали снижение исследуемого параметра на 3,9 ('Опал’) - 60,1% ('Золотоволоска'). Только у сорта 'Золотистый Дукат' выявлено увеличение показателя водоудерживающей способности в течение вегетационного периода на 5,7-6,0%.

Таким образом, по средним значениям водоудерживающей способности в течение вегетационного периода исследуемые сорта можно разделить на группы по засухоустойчивости: с высокой степенью устойчивости (ВС > 40 \% - 'Дебют', 'Загадка Осени', 'Казачка', 'Милашка', 'Опал', 'Перстень Королевы', 'Солнечная Феерия', 'Шапка Мономаха', 'Яблуневый Цвіт'); со средней степенью (ВС 31-40%'Estino Whito', 'Grandeur', 'Белоснежка', 'Відинский Бал', 'Вечерняя Симфония', 'Клара Кертис', 'Клеопатра', 'Пектораль', 'Плюшевый Мишка', 'Танго'); и с низкой степенью (BC $\leq 30$ \% - 'Akiwa Yellow', ‘Золотистый Дукат', ‘Золотоволоска', 'Солнышко'). 
В течение вегетационного периода была дана оценка водного дефицита листьев хризантем (табл. 2). Установлено, что в августе у 15 сортов данный показатель колебался от 0,0 ('Солнечная Феерия’) до 9,5 \% ('Клара Кертис'), т. е. находился в пределах нормы и не причинял вред растениям. У восьми сортов недостаток насыщения варьировал от 11,3 ('Казачка') до 21,1 \% ('Солнышко'), т. е. был немного выше нормы, но не достигал критических значений.

Таблица 2

\section{Оценка водного дефицита некоторых сортов хризантем}

\begin{tabular}{|c|c|c|c|c|c|c|c|}
\hline \multicolumn{2}{|l|}{ Сорта } & $\mathrm{Wg}$ & От & \multicolumn{2}{|c|}{ Сорта } & $\mathrm{Wg}$ & От \\
\hline \multirow{3}{*}{ 'Akiwa Yellow' } & $\mathrm{a}$ & 2,27 & 97,73 & \multirow{3}{*}{ 'Клеопатра' } & $\mathrm{a}$ & 2,86 & 97,14 \\
\hline & 6 & 17,55 & 82,45 & & 6 & 25,18 & 74,82 \\
\hline & B & 16,50 & 83,50 & & В & 13,95 & 86,05 \\
\hline \multirow{3}{*}{ 'Estino Whito’ } & $a$ & 3,44 & 96,56 & \multirow{3}{*}{ 'Милашка' } & $\mathrm{a}$ & 9,17 & 90,83 \\
\hline & 6 & 20,40 & 79,60 & & 6 & 22,63 & 77,37 \\
\hline & B & 17,41 & 82,59 & & B & 18,02 & 81,98 \\
\hline \multirow{3}{*}{ 'Grandeur' } & $\mathrm{a}$ & 17,81 & 82,19 & \multirow{3}{*}{ ‘Опал’ } & $\mathrm{a}$ & 12,99 & 87,01 \\
\hline & 6 & 21,00 & 79,00 & & 6 & 23,35 & 76,65 \\
\hline & B & 26,12 & 73,88 & & B & 20,47 & 79,53 \\
\hline \multirow{3}{*}{ ‘Белоснежка’ } & $\mathrm{a}$ & 3,15 & 96,85 & \multirow{3}{*}{ 'Пектораль' } & $\mathrm{a}$ & 5,77 & 94,23 \\
\hline & 6 & 21,39 & 78,61 & & 6 & 30,78 & 69,22 \\
\hline & B & 15,99 & 84,01 & & B & 22,06 & 77,94 \\
\hline \multirow{3}{*}{ ‘Відинский Бал’ } & $\mathrm{a}$ & 13,46 & 86,54 & \multirow{3}{*}{$\begin{array}{l}\text { 'Перстень } \\
\text { Королевы' }\end{array}$} & $\mathrm{a}$ & 4,37 & 95,63 \\
\hline & 6 & 28,29 & 71,71 & & 6 & 25,52 & 74,48 \\
\hline & В & 22,14 & 77,86 & & B & 15,75 & 84,25 \\
\hline \multirow{3}{*}{$\begin{array}{l}\text { 'Вечерняя } \\
\text { Симфония' }\end{array}$} & $\mathrm{a}$ & 16,46 & 83,54 & \multirow{3}{*}{$\begin{array}{l}\text { 'Плюшевый } \\
\text { Мишка' }\end{array}$} & $\mathrm{a}$ & 4,11 & 95,89 \\
\hline & 6 & 26,17 & 73,83 & & 6 & 28,19 & 71,81 \\
\hline & B & 14,98 & 85,02 & & B & 18,13 & 81,87 \\
\hline \multirow{3}{*}{ ‘Дебют’ } & $\mathrm{a}$ & 7,38 & 92,62 & \multirow{3}{*}{$\begin{array}{l}\text { ‘Солнечная } \\
\text { Феерия’ }\end{array}$} & $\mathrm{a}$ & 0,00 & 100,00 \\
\hline & 6 & 31,52 & 68,48 & & 6 & 24,96 & 75,04 \\
\hline & B & 25,45 & 74,55 & & B & 23,11 & 76,89 \\
\hline \multirow{3}{*}{ ‘Загадка Осени’ } & $\mathrm{a}$ & 3,09 & 96,91 & \multirow{3}{*}{ 'Солнышко' } & $\mathrm{a}$ & 21,05 & 78,95 \\
\hline & 6 & 25,85 & 74,15 & & 6 & 27,85 & 2,15 \\
\hline & B & 20,11 & 79,89 & & B & 16,07 & 83,93 \\
\hline \multirow{3}{*}{ ‘Золотистый Дукат’ } & $\mathrm{a}$ & 9,00 & 91,00 & \multirow{3}{*}{ ‘Танго’ } & $\mathrm{a}$ & 7,83 & 92,17 \\
\hline & 6 & 21,68 & 78,32 & & 6 & 22,98 & 77,02 \\
\hline & B & 21,48 & 78,52 & & B & 18,53 & 81,47 \\
\hline \multirow{3}{*}{ ‘Золотоволоска’ } & $\mathrm{a}$ & 1,33 & 98,67 & \multirow{3}{*}{$\begin{array}{l}\text { 'Шапка } \\
\text { Мономаха' }\end{array}$} & $\mathrm{a}$ & 12,88 & 87,12 \\
\hline & 6 & 40,16 & 59,84 & & 6 & 21,40 & 78,60 \\
\hline & B & 21,22 & 78,78 & & B & 27,91 & 72,09 \\
\hline
\end{tabular}


Глава 6. Физиология и биохимия растений

\begin{tabular}{|c|c|c|c|c|c|c|c|}
\hline \multirow{3}{*}{ ‘Казачка' } & $\mathrm{a}$ & 11,28 & 88,72 & \multirow{3}{*}{$\begin{array}{l}\text { 'Яблуневый } \\
\text { Цвіт' }\end{array}$} & $\mathrm{a}$ & 17,07 & 82,93 \\
\hline & 6 & 21,05 & 78,95 & & 6 & 40,18 & 59,82 \\
\hline & B & 10,56 & 89,44 & & B & 17,31 & 82,69 \\
\hline \multirow{3}{*}{ 'Клара Кертис’ } & $\mathrm{a}$ & 9,50 & 90,50 & & & & \\
\hline & 6 & 16,73 & 83,27 & & & & \\
\hline & B & 14,44 & 85,56 & & & & \\
\hline
\end{tabular}

Примечание: $\mathrm{Wg}$ - водный дефицит;

От - относительная тургесцентность;

а - август; б - сентябрь, в - октябрь

В сентябре у большинства сортов значения водного дефицита увеличилась в $1,2-8,8$ раза, а у двух сортов - 'Солнечная Феерия' и 'Золотоволоска' - в 25,0 и 30,2 раза по сравнению с показателями августа. Максимальные значения дефицита насыщения отмечены у сортов 'Золотоволоска' и 'Яблуневый Цвіт' (40,2%). У остальных сортов данный показатель приближался или был немного выше критических значений. Однако при таких значениях водного дефицита у исследуемых растений не было отмечено негативных последствий.

В октябре у большинства сортов отмечалось сокращение величины водного дефицита в 1,1-2,3 раза по сравнению с показателями сентября. У трёх сортов ('Grandeur', 'Клара Кертис', 'Шапка Мономаха') дефицит насыщения увеличился в 1,2-1,3 раза по сравнению с данными сентября. У сорта 'Золотистый Дукат' остался на прежнем уровне.

Для разделения сортов по засухоустойчивости существуют шкалы, разработанные для сельскохозяйственных культур [3]. Опираясь на полученные результаты, мы разработали подобную шкалу для хризантем (табл. 3).

Таблица 3

Устойчивость водного режима Chrysanthemum

\begin{tabular}{|l|c|c|c|}
\hline \multirow{2}{*}{ Параметры } & \multicolumn{3}{c|}{ Степень устойчивости } \\
\cline { 2 - 4 } & высокая & средняя & низкая \\
\hline Общая оводнённость тканей, $\%$ & $\geq 80$ & $60-79$ & $\leq 59$ \\
\hline Водоудерживающая способность, \% & $\geq 40$ & $3-40$ & $\leq 30$ \\
\hline Водный дефицит, \% & $0-10$ & $11-25$ & $\geq 26$ \\
\hline
\end{tabular}

На основании средних значений водоудерживающей способности, общей оводнённости и водного дефицита листьев сорта хризантем дифференцированы на три группы: с высокой (4 сорта), средней (15 сортов) и низкой засухоустойчивостью (4 сорта) (рис. 1). 


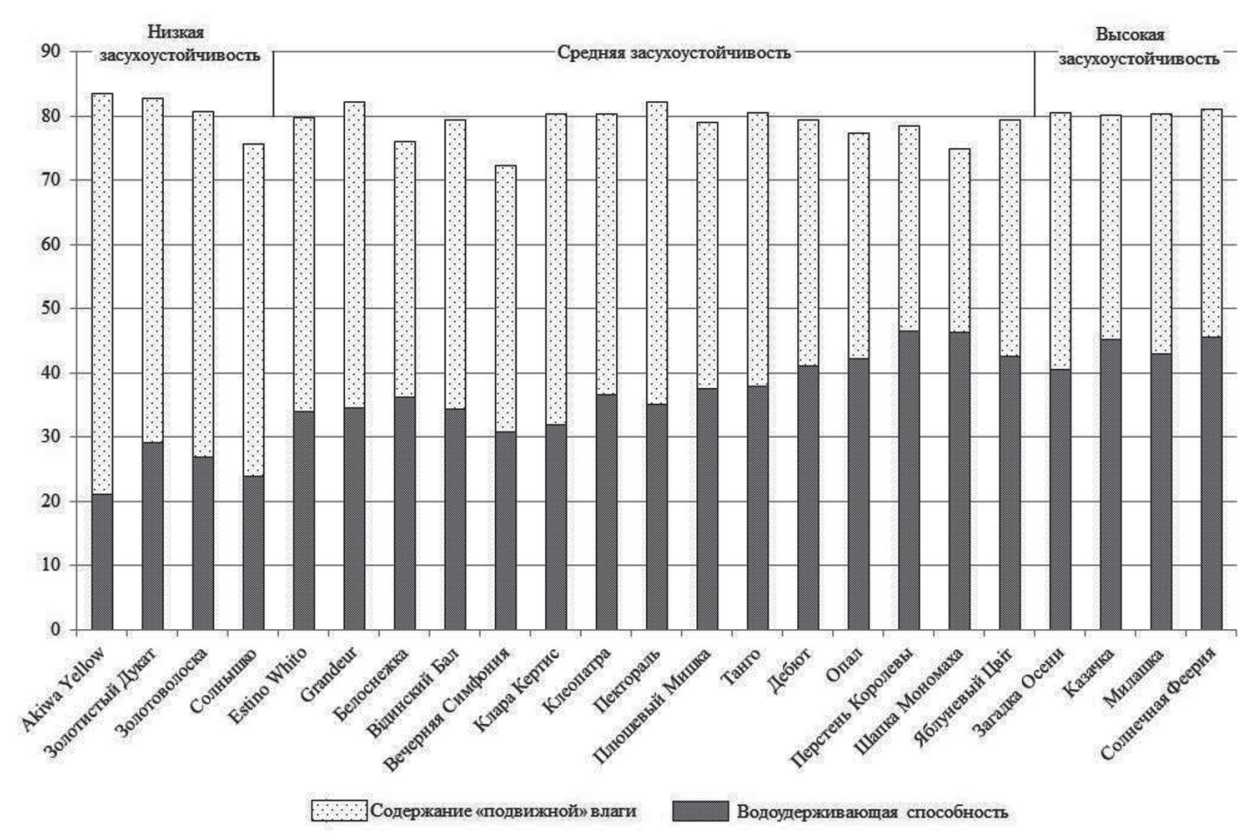

Рис. 1. Классификация хризантем по степени засухоустойчивости

Заключение. При определении водного дефицита листьев было отмечено, что у изученных сортов хризантем на протяжении вегетационного периода не возникало такого дефицита влаги в тканях, который мог бы привести к необратимым повреждениям ассимилирующих органов. Наши исследования показали, что сорта хризантем в условиях Башкирского Предуралья при одинаковых почвенно-климатических и агротехнических условиях имели различные степени засухоустойчивости. Засухоустойчивыми оказались сорта 'Загадка Осени', 'Казачка', 'Милашка', 'Солнечная Феерия'. Среднюю степень засухоустойчивости проявили сорта 'Estino Whito', 'Grandeur', 'Белоснежка', 'Відинский Бал', 'Вечерняя Симфония', 'Дебют’, 'Клара Кертис', 'Клеопатра', 'Опал', 'Пектораль', 'Перстень Королевы', 'Плюшевый Мишка', 'Танго', 'Шапка Мономаха', 'Яблуневый Цвіт'. К группе менее засухоустойчивых отнесены сорта 'Akiwa Yellow', 'Золотистый Дукат', ‘Золотоволоска', 'Солнышко'. В целом изученные сорта хризантем оказались пригодными для выращивания в условиях Башкирского Предуралья.

Благодарности

Работа выполнена по Программе фундаментальных исследований Президиума РАН «Биоразнообразие природных систем и биологические ресурсы России» и в рамках государственного задания ЮУБСИ УФИЦ РАН 
Глава 6. Физиология и биохимия растений

\title{
Библиографический список
}

1. Гусев Н.А. Некоторые методы исследования водного режима растений. - Л.: АН СССР, Всесоюзное ботаническое общество, 1960. - 60 с.

2. Зайцев Г.Н. Математический анализ биологических данных. - М.: Наука, 1991. 184 c. - ISBN 5-02-004133-5.

3. Гончарова Э.А. Оценка устойчивости к разным стрессам плодово-ягодных и овощных (сочноплодных) культур // Диагностика устойчивости растений к стрессовым воздействиям: метод. руководство / под. ред. д.б.н., проф. Г.В. Удовенко. - Л.: ВИР, 1988. - С. 46-62. 4. Иванова А.В. Водный дефицит - проявление стресса у Thuja occidentalis // Фундаментальные и прикладные проблемы стресса: мат. междунар. науч.-практ. конф., Витебск, 10 июня, 2010 г. - Витебск: ВГУ им. П.М. Машерова, 2010. - С. 184-187.

5. Кротова 3.Е. Эколого-биологические основы интродукции растений в Якутии // Интродукция растений Сибири и Дальнего Востока. - Новосибирск: Наука, 1983. - С. 90-97. 6. Кушниренко М.Д., Печерская С.Н. Физиология водообмена и засухоустойчивости растений. - Кишинѐв: Штиинца, 1991. - 305 с. - ISBN 5-376-00675-1.

7. Лищук А.И. Засухо- и жароустойчивость плодовых косточковых пород в условиях Крыма // Вопросы интродукции и акклиматизации растений. - М.: Наука, 1991. - С. 113.

8. Моисеев В.П., Решецкий Н.П. Физиология и биохимия растений. Издание 2-ое, дополненное и переработанное: методические указания. - Горки: Белорусская государственная сельскохозяйственная академия, 2009. - 124 с.

9. Пахомова Г.И., Безуглов В.К. Водный режим растений. - Казань: Изд-во Казанского университета, 1980. - 252 с.

10. Петухова И.П. Некоторые показатели динамики водного режима, зелёных пигментов и активность пероксидазы у ряда древесных растений в связи с интродукцией на юг Приморья // Экологическая физиология зимостойкости древесных растений на Дальнем Востоке. - Владивосток: ДВНЦ АН СССР, 1977. - С. 29-42.

11. Таренков В.А., Иванова Л.Н. Водоудерживающая способность листьев боярышников в связи с устойчивостью к засухе // Интродукция, акклиматизация, охрана и использование растений. - Куйбышев: Куйбышевский госуниверситет, 1990. - С. 3-9. 12. Чиркова Т.В. Физиологические основы устойчивости растений. - СПб.: СПбГУ, 2002. - 244 c. - ISBN 5-288-02413-8.

13. Prasad P.V., Staggenborg S.A., Ristic Z. Impacts of drought and heat stress on physiological, developmental, growth, and yiend processes of crop plants // Advances in Agricultural Sistem Modeling. Series 1. - 2008. - P. 301-355.

\section{WATER REGIME OF CHRYSANTHEMUM REPRESENTATIVES DURING INTRODUCTION IN THE SOUTH URAL}

\author{
Denisova S. G., Reut A. A. \\ South-Ural Botanical Garden-Institute - Separate Structural Subdivision \\ of the Federal State Budgetary Scientific Institution Ufa \\ Federal Research Centre of the Russian Academy of Sciences, \\ Ufa, Russia, e-mail: svetik-7808@mail.ru
}

The paper presents a comparative study of the water regime in 23 chrysanthemum cultivars introduced to the South-Ural Botanical Garden-Institute - Separate Structural Subdivision of the Federal State Budgetary Scientific Institution Ufa 
Federal Research Centre of the Russian Academy of Sciences. The total water content, water retention capacity, daily loss of moisture and water deficit during the growing season 2018-2019 were estimated. It is shown that in the conditions of Bashkir Pre-Ural, chrysanthemum cultivars have different degrees of drought resistance under the same soil-climatic and agrotechnical conditions. In general, the studied chrysanthemum cultivars were suitable for growing in the forest-steppe zone of Bashkir Pre-Ural.

Key words: chrysanthemum, water regime, total water content, water retention capacity, water deficit.

УДК 581.1:633.72

doi: 10.31360/2225-3068-2020-74-120-131

\title{
ВЛИЯНИЕ РЕГУЛЯТОРОВ РОСТА РАСТЕНИЙ НА ФУНКЦИОНАЛЬНЫЕ ПРОЦЕССЫ СЕЛЬСКОХОЗЯЙСТВЕННЫХ КУЛЬТУР (литературный обзор)
}

\author{
Лагошина А. Г. ${ }^{1}$, Пчихачев Э. К. ${ }^{1}$, Белоус О. Г. ${ }^{2}$ \\ ${ }^{2}$ Адыгейский филиал \\ Федеральное государственное бюджетное учреждение науки \\ «Федеральный исследовательский ияентр «Субтропический научный изентр \\ Российской академии наук» \\ ${ }^{2}$ Федеральное государственное бюджетное учреждение науки \\ «Федеральный исследовательский ичентр «Субтропический научный ичентр \\ Российской академии наук» \\ n. Цветочный, Республика Aдыгея, e-mail: Gvenvivare@mail.ru
}

В работе представлен анализ литературных источников по исследованию влияния регуляторов роста на физиологические процессы растений, лежащие в основе повышения адаптивности сельскохозяйственных культур и их продуктивности. Показано, что адаптационные процессы растений можно усилить использованием биологически активных веществ, представляющих собой физиологически активные соединения, способные в малых количествах вызывать изменения процессов роста и развития растений. Отмечено, что культура чая в республике Адыгея подвержена целому ряду стрессовых факторов, связанных с климатическими особенностями региона, и эффективность применения регуляторов роста на растениях чая является актуальным направлением экологичных технологий возделывания чайных насаждений в регионе. Приведены данные первого года исследований по использованию регуляторов роста на плантации чая, показавших активацию механизма устойчивости растений чая при некорневых обработках регуляторами роста.

Ключевые слова: чай, регуляторы роста, аминокислоты, гуминовые кислоты, стресс-факторы, продуктивность, качество, устойчивость. 